\title{
BYPASS VS. SLEEVE AND ITS EFFECTS IN NON-ALCOHOLIC FATTY LIVER DISEASE: WHAT IS THE BEST TECHNIQUE?
}

\author{
Bypass vs. sleeve e seus resultados na doença hepática gordurosa não alcoólica: Qual a melhor técnica?
}

\author{
Marcos Bertozzi GOLDONI ${ }^{\oplus}$, Paulo Roberto Ott FONTES ${ }^{1 \oplus}$,Marcela Menuci GUIMARÃES ${ }^{1 \oplus}$, João \\ Alfredo DIEDRICH-NETO ${ }^{1 \oplus}$, Tiele NOGUEIRA ${ }^{1}{ }^{\oplus}$, Uirá Fernandes TEIXEIRA ${ }^{1 \oplus}$, Caroline Becker \\ GIACOMAZZI $^{1 \oplus}$, Guillermo KISS ${ }^{2}$, Sérgio Ricardo PIONER ${ }^{2 \oplus}$, Pablo Duarte RODRIGUES ${ }^{\oplus}$
}

\begin{abstract}
Background: Strongly associated with obesity, non-alcoholic fatty liver disease is considered the hepatic manifestation of the metabolic syndrome. It presents as simple steatosis and steatohepatitis, which can progress to cirrhosis and its complications. Among the therapeutic alternatives is bariatric surgery. Aim: To compare the effect of the two most frequent bariatric procedures (sleeve and bypass) on liver disease regarding to epidemiological, demographic, clinical and laboratory parameters. Methods: The results of intraoperative and 12 months after surgery liver biopsies were used. The NAFLD activity score (NAS) was used to assess and compare the stages of liver disease. Results: Sixteen (66.7\%) patients underwent Bypass procedure and eight (33.3\%) Sleeve. It was observed that the variation in the NAFLD activity score was significantly greater in the Bypass group than in Sleeve $(p=0.028)$ and there was a trend regarding the variation in fibrosis $(p=0.054)$. Conclusion: Both surgical techniques were effective in improving the hepatic histology of most operated patients. When comparing sleeve and bypass groups, bypass showed better results, according to the NAS score.
\end{abstract}

HEADINGS: Bypass. Sleeve. Non-alcoholic fatty liver disease. Morbid obesity. Bariatric surgery.

RESUMO - Racional: Fortemente associada à obesidade, a doença hepática gordura não alcoólica é considerada a manifestação hepática da síndrome metabólica. Ela apresenta-se como esteatose simples e esteato-hepatite, podendo evoluir para cirrose e suas complicações. Entre as alternativas terapêuticas está a cirurgia bariátrica. Objetivo: Comparar o efeito sobre a doença hepática dos dois procedimentos bariátricos mais frequentes - sleeve e bypass - e comparar dados epidemiológicos, demográficos, parâmetros clínicos e laboratoriais. Métodos: Utilizou-se o resultado das biópsias hepáticas realizadas no intra-operatório e 12 meses após a operação. O NAFLD activity score foi utilizado para avaliar e comparar os estágios da doença hepática. Resultados: Dezesseis $(66,7 \%)$ pacientes foram submetidos ao bypass e oito $(33,3 \%)$ ao sleeve. Observou-se melhora significativa no IMC e glicemia nas duas técnicas cirúrgicas enquanto que os níveis de fosfatase alcalina, ferritina, Gama-GT e TGP reduziram com significância apenas no grupo bypass. A redução no NAFLD activity score foi significativamente maior no grupo bypass que no sleeve $(p=0,040)$. Conclusão: Ambas as técnicas foram eficazes em promover a melhora da histologia hepática da maior parte dos pacientes operados. Quando comparadas o bypass apresentou melhores resultados.

DESCRITORES: Bypass. Sleeve. Doença hepática gordurosa não alcoólica. Obesidade mórbida. Cirurgia bariátrica.

\begin{tabular}{|l|}
\hline Central message \\
\hline When comparing the liver effects of the two most \\
frequent bariatric procedures - sleeve and bypass \\
- both were effective in promoting histological \\
improvement of non-alcoholic fatty liver disease. \\
When compared, bypass provided better results. \\
\hline
\end{tabular}

\begin{tabular}{l}
\hline Perspectives \\
Non-alcoholic fatty liver disease is considered the \\
hepatic manifestation of the metabolic syndrome \\
and has bariatric surgery as a alternative treatment. \\
Both most frequent techniques - sleeve and bypass \\
- were effective in promoting liver histological \\
improvement. When compared using the NAFLD \\
activity score, bypass provided better results being \\
the surgery of choice for this situation. A larger \\
number of studies, mainly randomized control trials, \\
are needed to confirm this hypothesis.
\end{tabular}




\section{INTRODUCTION}

$\mathrm{N}$ on-alcoholic fatty liver disease (NAFLD) has a global distribution and is considered nowadays the most common liver disease in the west industrialized countries, probably because of the association with obesity, type 2 diabetes (DM2), dyslipidemia and metabolic syndrome. The prevalence of NAFLD is reported as 6-35\%, with an average of $20 \%$, in the general population ${ }^{33}$.

There is a strong evidence that NAFLD represents the hepatic component of the metabolic syndrome, characterized by obesity, hyperinsulinemia, insulin resistance (IR), DM2, hypertriglyceridemia and systemic arterial hypertension (SAH). Obesity is a common and well-documented risk factor for NAFLD. In patients with severe obesity undergoing bariatric surgery, the prevalence of NAFLD can exceed $90 \%$, with up to $50 \%$ of patients presenting steatohepatitis (NASH) and $5 \%$ cirrhosis ${ }^{6,25}$

Abdominal ultrasound is widely used as the first line in the investigation of NAFLD and evidence the accumulation of fat when more than 33\% of hepatocytes have steatosis. Liver biopsy is the gold standard method for the diagnosis of NAFLD, being able to assess the degree of fatty infiltration, hepatocellular damage, inflammation and fibrosis. The presence of hepatocellular ballooning in association with steatosis is the key to the differential diagnosis between simple steatosis and $\mathrm{NASH}^{29}$.

All patients with NAFLD should undergo interventions to promote a healthier lifestyle and strict control of the metabolic risk factors associated with NAFLD ${ }^{17}$. Weight loss is the most important factor. Relatively small losses of approximately $7-10 \%$ of body weight in 12 months seem to be effective in improving NAFLD already ${ }^{11,20}$.

Obesity and DM2, isolated or linked by metabolic syndrome, are the most important risk factors in the genesis of NAFLD. The role of bariatric surgery comes up in this context. Several consistent studies over the past few years, culminating in the publication of Philip Schauer in $2017^{31}$, have shown that surgical treatment is more effective in weight loss and in the control of glycemia and metabolic syndrome than intensive and optimized clinical treatment in the short, medium and long terms.

Although there are still no randomized clinical trials evaluating the role of bariatric surgery in the treatment of NAFLD, there are several retrospective and prospective studies in the literature, in addition to a few meta-analyzes, which evaluate the effect of surgical treatment on NAFLD 1-3,5,8-10,12-14,16,20,21,23-26,32,34. The AASLD and EASL guidelines define bariatric surgery as a therapeutic option in NAFLD, mainly in those patients who did not respond to conservative clinical treatment ${ }^{11,20}$.

Roux-en-Y bypass (bypass) and vertical gastrectomy (sleeve) have been compared in several studies to determine which one has the greatest benefit in weight loss or in resolving obesity-related comorbidities. However, there is few knowledge about which of these techniques is associated with the best results on NAFLD. There are few comparative studies and these are small series with a large number of biases, such as heterogeneity of groups and assessment systems ${ }^{7,15,28}$.

In a group of obese patients, the main objective of the present study was to compare the bariatric sleeve and Rouxen- $Y$ bypass techniques and their effects on NAFLD, also in epidemiological, demographic, clinical and laboratory parameters.

\section{METHODS}

The study was submitted to and approved by the Ethics Committee of the institution, where it was carried out. CAAE: 90475215500005335.

\section{Patients selection}

A retrospective study that evaluated patients undergoing bariatric surgical procedures by the same surgical team, between 2014 and 2016, at Irmandade da Santa Casa de Misericórdia de Porto Alegre, Porto Alegre, RS, Brazil.

Only patients with intraoperative and postoperative liver biopsy were included. The average time between biopsies was 12 months.

Demographic characteristics (gender and age), clinical parameters (weight, height, BMI, SAH, weight loss, excess weight lost) and laboratory (platelets, ALP, ferritin, GGT, AST, ALT), histopathological analysis and NAS score ${ }^{16}$ were collected and analyzed.

\section{Operative technique}

All procedures were performed laparoscopically.

The sleeve surgery was made with the dissection of the greater gastric curvature $3 \mathrm{~cm}$ from the pylorus to the esophagogastric flexure. The gastric transection was calibrated with a $36 \mathrm{~F}$ bougie and reinforcing the staple line with continuous suture with Caprofyl ${ }^{\oplus}$ 2.0.

In the bypass surgery, a $4 \mathrm{~cm}$ gastric pouch was done using a $36 \mathrm{~F}$ bougie. The Roux limb used to be $100 \mathrm{~cm}$ and the biliopancreatic limb used to be $150 \mathrm{~cm}$. Gastroenteric anastomosis was performed laterally with a linear stapler calibrated by a 36F bougie.

\section{Histopathological evaluation}

All liver samples were analyzed in the hospital's pathology laboratory by a single professional experienced in liver pathology. The NAFLD activity score (NAS) was used to assess and compare the stages of liver disease ${ }^{18}$. It proposes the characterization of NAFLD regarding the degree of steatosis, the presence of ballooning and inflammation activity. NAS scores the histological analysis from 0 to 3 : degree of steatosis (0-3), lobular inflammation $(0-3)$ and ballooning (0-2). The degree of fibrosis was assessed semi-quantitatively with a scale of 0 to 4 .

\section{Statistical analysis}

Categorical results were presented using frequency and percentage and were analyzed using the $X^{2}$ test (chi-square). The likelihood-ratio test was performed in comparisons when there were more than $20 \%$ of the cells with an expected value below $20 \%$. Quantitative results were displayed using means \pm standard deviations and when data followed normal distribution it was analyzed using Student's t tests for paired and independent samples; when non-parametric, the Wilcoxon and MannWhitney tests were used. The normality of the data was verified using the Shapiro-Wilk test. The variation in the NAS score was calculated using the difference between the postoperative and the intraoperative score. The analyzes were performed using SPSS software, version 21 and significant results were considered when $\mathrm{p}<0.05$.

\section{RESULTS}

Twenty-four obese patients who underwent bariatric surgery were evaluated, of which 16 (66.7\%) undergoing bypass and eight sleeve, with a mean segment time of $21.3 \pm 16$ months and $15.5 \pm 12.5$ months, respectively $(p=0.380) .68 .8 \%$ of patients undergoing bypass were women, on the sleeve group, $75 \%(p=0.571) ; 31.3 \%$ were hypertensive vs. $37.5 \%$ in the sleeve $(p=0.553)$; in the bypass group, age and maximum weight were $38.6 \pm 11.3$ years and $119.1 \pm 14.1 \mathrm{~kg}$ respectively vs. $36.7 \pm 8.4$ years, $p=0.692$ and $119.1 \pm 13.5, p=0.999$ in the sleeve group. Furthermore, the two techniques were also similar in terms of weight loss $(44.2 \pm 15.1 \mathrm{~kg}$ vs. $37.9 \pm 7.4 \mathrm{~kg}, \mathrm{p}=0.180$, respectively) and the excess weight lost $(84.4 \pm 29,8 \mathrm{~kg}$ vs. $83.2 \pm 26.8 \mathrm{~kg}, \mathrm{p}=0.904$, respectively).

Table 1 shows the results of the clinical and laboratory 
parameters in the preoperative period and after the surgical procedures. In both periods and in all parameters analyzed, no difference was found between the techniques with statistical significance. However, there were significant reductions in BMI and glycemia in the two techniques analyzed, while reductions in alkaline phosphatase, ferritin, GGT and ALT were significant only in the bypass group.

TABLE 1 - Pre and postoperative clinical and laboratory parameters according to the type of operation performed.

\begin{tabular}{|c|c|c|c|c|}
\hline Parameter & Technique & Pre-op & Post-op & $p$ \\
\hline \multirow{3}{*}{ BMI $\left(\mathrm{kg} / \mathrm{m}^{2}\right)$} & Bypass & $44.3 \pm 4.2$ & $27.9 \pm 4.1$ & $<0.001$ \\
\hline & Sleeve & $42.1 \pm 4.1$ & $28.6 \pm 5.8$ & $<0.001$ \\
\hline & $\mathrm{p}$ & 0.239 & 0.730 & \\
\hline \multirow{3}{*}{ Platelets (x1000) } & Bypass & $270 \pm 59$ & $239 \pm 66$ & 0.170 \\
\hline & Sleeve & $283 \pm 45$ & $279 \pm 71$ & 0.832 \\
\hline & $\mathrm{p}$ & 0.606 & 0.191 & \\
\hline \multirow{3}{*}{$\operatorname{ALP}(\mathrm{U} / \mathrm{L})$} & Bypass & $92.2 \pm 30.7$ & $72.8 \pm 16.8$ & 0.010 \\
\hline & Sleeve & $105.5 \pm 20.6$ & $103.0 \pm 70.3$ & 0.910 \\
\hline & $\mathrm{p}$ & 0.283 & 0.268 & \\
\hline \multirow{3}{*}{ Ferritin (ng/ml) } & Bypass & $227.1 \pm 150.3$ & $121.1 \pm 86.4$ & 0.011 \\
\hline & Sleeve & $232.6 \pm 76.1$ & $133.6 \pm 103.1$ & 0.069 \\
\hline & $p$ & 0.854 & 0.976 & \\
\hline \multirow{3}{*}{ GGT (U/L) } & Bypass & $55.9 \pm 31.1$ & $19.1 \pm 10.8$ & 0.000 \\
\hline & Sleeve & $111.0 \pm 151.8$ & $64.5 \pm 116.3$ & 0.123 \\
\hline & $p$ & 0.312 & 0.197 & \\
\hline \multirow{3}{*}{ Glycemia (mg/dl) } & Bypass & $99.4 \pm 17.2$ & $82.1 \pm 9.8$ & 0.001 \\
\hline & Sleeve & $102.75 \pm 10.2$ & $90.2 \pm 8.6$ & 0.007 \\
\hline & $p$ & 0.616 & 0.059 & \\
\hline \multirow{3}{*}{ AST (U/L) } & Bypass & $30.8 \pm 16.2$ & $25.5 \pm 6.9$ & 0.338 \\
\hline & Sleeve & $33.5 \pm 12.2$ & $39.0 \pm 27.9$ & 1.000 \\
\hline & $p$ & 0.408 & 0.358 & \\
\hline \multirow{3}{*}{ ALT (U/L) } & Bypass & $42.1 \pm 20.6$ & $28.3 \pm 10.6$ & 0.023 \\
\hline & Sleeve & $39.9 \pm 12.5$ & $31.6 \pm 13.2$ & 0.207 \\
\hline & p- & 0,806 & 0,602 & \\
\hline
\end{tabular}

$\mathrm{BMI}=$ body mass index; $\mathrm{ALP}=$ alkaline phosphatase; $\mathrm{GGT}=$ gamma glutamy transpeptidase; $\mathrm{AST}=$ aspartate aminotransferase; $\mathrm{ALT}=$ alanine aminotransferase

Evaluating the evolution of the NAFLD degree on the second biopsy compared to the first, 19 (79.2\%) patients showed improvement, two (8.3\%) remained in the same degree and three (12.5\%) worsened. There was a significant association between the evolution of NAFLD and the surgical procedure performed $(p=0.024)$. In the sleeve group, three (37.5\%) worsened the level of NAFLD vs. no patient in the bypass group (Figure 1).

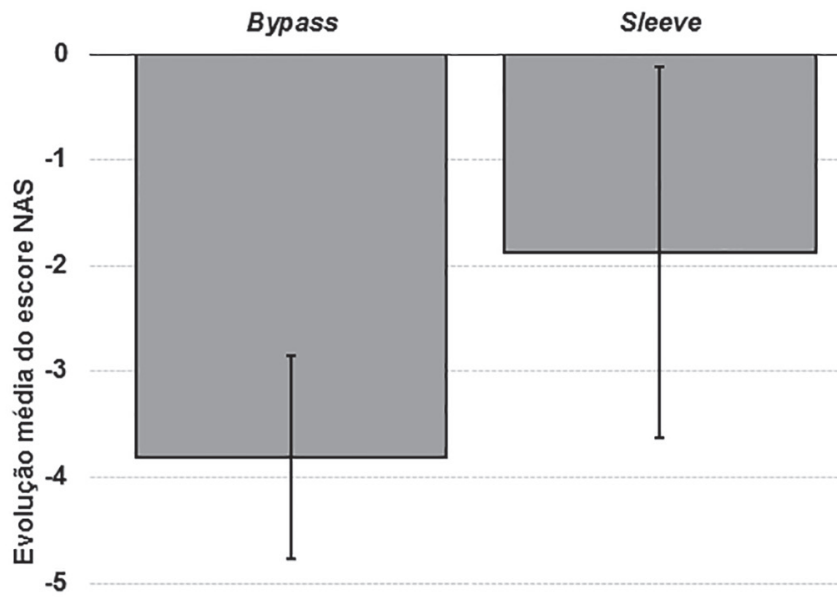

\section{FIGURE 1 - Evolution of NAFLD degree}

Table 2 shows the differences in the NAS ${ }^{16}$ classification between the first and second biopsies. In all categories, a significant reduction was observed when the technique was bypass. However, in the sleeve group, only steatosis and the NAS score showed significant reductions.
TABLE 2 - Comparison between the first and second liver biopsies

\begin{tabular}{|c|c|c|c|c|}
\hline $\begin{array}{c}\text { NAS classification } \\
\text { Bypass }\end{array}$ & First & Second & Change & $p$ \\
\hline $\begin{array}{c}\text { Steatosis } \\
\text { Inflammation }\end{array}$ & $2.0 \pm 0.8$ & $0.2 \pm 0.4$ & $-1.81 \pm 0.91$ & $<0.001$ \\
\hline Ballooning & $1.5 \pm 0.7$ & $0.5 \pm 0.5$ & $-0.75 \pm 0.77$ & 0.005 \\
\hline Fibrosis & $0.9 \pm 1.0$ & $0.2 \pm 0.7$ & $-1.25 \pm 1.00$ & 0.002 \\
\hline NAS score & $4.8 \pm 1.7$ & $0.9 \pm 1.3$ & $-0.69 \pm 0.87$ & 0.015 \\
\hline Sleeve & & & & \\
\hline Steatosis & $1.5 \pm 0.7$ & $0.2 \pm 0.5$ & $-1.25 \pm 0.89$ & 0.014 \\
\hline Inflammation & $0.7 \pm 0.9$ & $0.7 \pm 0.5$ & $-0.13 \pm 0.64$ & 0.564 \\
\hline Ballooning & $1.0 \pm 1.1$ & $0.5 \pm 0.9$ & $-0.50 \pm 1.41$ & 0.317 \\
\hline Fibrosis & $0.4 \pm 0.7$ & $0.6 \pm 0.9$ & $0.25 \pm 1.39$ & 0.581 \\
\hline NAS score & $3.2 \pm 1.8$ & $1.4 \pm 1.7$ & $-1.87 \pm 2.10$ & 0.048 \\
\hline
\end{tabular}

The intensity of variations was compared between groups with no significant difference between them ( $p>0.05)$, except for the NAS score shown in Figure 2, whose reduction observed in the bypass was significantly higher than in the sleeve $(-3,81 \pm 1,80$ vs. $-1,87 \pm 2,10$, respectively; $p=0,040$ ).

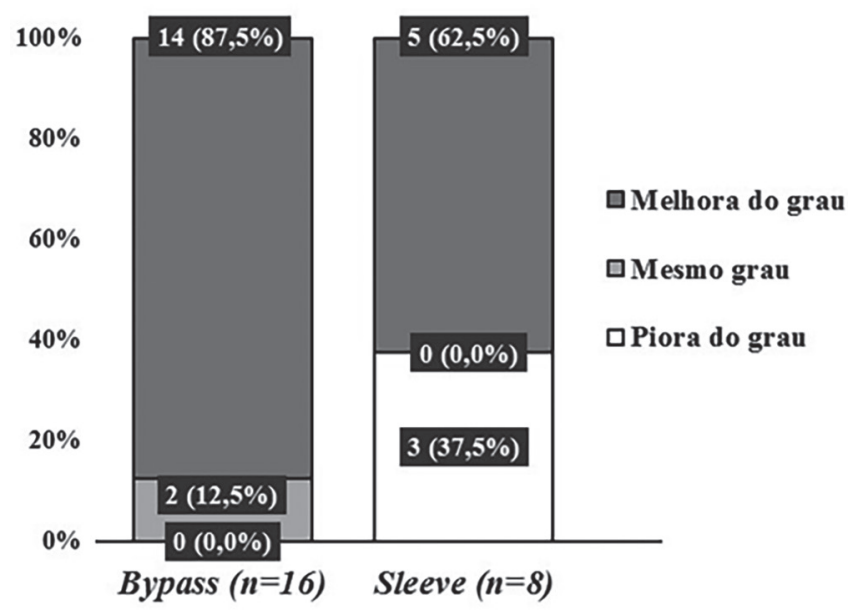

FIGURE 2 - Comparison of the mean variation of the NAS score

\section{DISCUSSION}

In our country, bypass is still the most performed bariatric technique; but, in recent years, there has been an important increase in the number of vertical gastrectomy, which follows the worldwide trend of technical preference nowadays ${ }^{4}$.

Historically, patients with morbid obesity or those with clinical signs and symptoms of metabolic syndrome had in the operations of mixed character (bypass) - with restrictive and disabsorptive component -, their most frequent indication. Purely restrictive procedure - vertical gastrectomy - a relatively newer technique, was initially indicated for patients with grade II obesity or very high BMI levels greater than $60 \mathrm{~kg} / \mathrm{m}^{2}$, those in which the necessary weight loss was not too much or those that mixed operations has became impractical due to the great excess of weight. Thus, sometimes it becomes difficult to compare the results between the techniques, since the patients generally presented important clinical and epidemiological differences, making statistically different groups.

Inthe presentstudy, evaluating the demographic characteristics of both groups - bypass and sleeve - it was noticed that there were no statistical differences between them. Gender, breed and age were similar. SAH was present in approximately $30 \%$ of patients. There were no diabetic patients and the mean blood glucose was practically the same in both groups, $100 \mathrm{mg} / \mathrm{dl}$. Regarding weight, BMI, laboratory tests - platelets, alkaline phosphatase, ferritin, gamma-GT, glycemia, AST and ALT preoperatively - the groups also showed similarity. This parity between the groups 
contributes to a more reliable comparative analysis with a lower incidence of bias.

Already widely discussed and consolidated in the literature, these bariatric procedures have an important effect on weight loss. In the present study, in the mean follow-up of 12 months, the BMl showed an average reduction of $16.3 \pm 5.23 \mathrm{~kg} / \mathrm{m}^{2}$ and $13.4 \pm 2.7 \mathrm{~kg} / \mathrm{m}^{2}$ in the bypass and sleeve, respectively. This reduction represents the average loss of approximately $84 \%$ of excess body weight for both techniques. As previously published by several authors, and more recently by Peterli et al ${ }^{27}$, the tendency is not to have statistical differences between bypass and sleeve considering weight loss in the short, medium and long terms.

Analyzing blood glucose separately, it was observed that both surgical techniques were effective, statistically reducing serum glucose levels by $17.3 \pm 15.7 \mathrm{mg} / \mathrm{dl}$ and $12.5 \pm 9.4 \mathrm{mg} / \mathrm{dl}$, considering bypass and sleeve respectively. When comparing the final results between the techniques, there is a favorable trend towards bypass $(p=0.059)$, probably depending on a larger sample. In recent years, it has been associated with techniques with intestinal deviation, a condition of metabolic change that would provide better results on glycemic control, compared to purely restrictive techniques. The increase in intestinal hormones such as glucagon-like peptide-1 (GLP-1) and peptide YY(PYY), the result of the food's earlier contact with the ileum, would be responsible for this fact. However, more recently, although there is no established pathophysiological explanation, there are studies showing a similar result between the sleeve and bypass regarding glycemic control ${ }^{30}$.

Analyzing the other laboratory tests evaluated in the study, we observed that in the bypass group there was a significant improvement in the levels of alkaline phosphatase, ferritin, gammaGT and ALT, which did not occur in the sleeve. AST and platelets showed no significant changes.

As previously mentioned, the mechanism by which bariatric surgery performs potential treatment for NAFLD is complex and has not been fully elucidated yet. It is probably related to improvement of factors such as insulin resistance, lipid profile, inflammation, weight loss and adipokines, which are directly involved in the development of metabolic syndrome and, consequently, in its hepatic phenotype, NAFLD. These changes are seen right after the surgical procedure, during the phase when weight loss is not yet significant. It is well established that weight loss plays a fundamental role in the control of metabolic abnormalities; however, endocrinophysiological changes resulting from the operation may have a more relevant effect in the long term on NAFLD. These findings have been confirmed by several studies published in the international literature. As in the present study, NAFLD in its several stages, simple steatosis, NASH and fibrosis, showed significant improvement after the bariatric procedure, be it bypass or sleeve 19,10,13,14,16,19,21,22,23.

However, it can be noticed that part of the operated patients does not improve or could get a worse level of NAFLD, which ranges from $7-20 \%$ of patients ${ }^{22,23,32}$. In the present study, it was observed that five patients (20.8\%) did not demonstrate complete resolution of NAFLD. Of these, three (12.5\%) showed disease progression, all in the sleeve group.

In the quantitative analysis of NAFLD, the bypass group showed between the first and second biopsies, significant improvement in all NAS parameters (steatosis, inflammation and ballooning), in fibrosis and in the NAS score itself. In the sleeve group, statistical significance was observed only in the steatosis and in the NAS score. Comparing the change in the NAS score between the first and second biopsies, it was observed that this was significantly higher in the bypass group $(-3.81 \pm 1.80$ vs. $-1.87 \pm 2.10 ; p=0.040)$.

In line with the literature, in the present study there was a significant improvement in NAFLD after bariatric procedures, both in the purely restrictive operation (sleeve) and in the mixed operation (bypass).

However, unlike the previous findings published by Froylich ${ }^{15}$, Billeter $^{7}$ and Praveen ${ }^{28}$, who presented the operative results on
NAFLD comparing the sleeve and bypass techniques and did not find statistical differences or tended to the sleeve as the best results procedure, in the present study, the bypass had better effects on NAFLD, including a statistical difference when considering the evolution of the NAS score. There is currently no clear explanation, but it is likely that anatomical changes, particularly duodenal exclusion, increased flow of nutrients to the distal small intestine and the resulting hormonal and metabolic changes related to bypass are responsible for these findings.

The retrospective nature of the study, the small number of patients in the groups and the possible selection biases are important limitations that must be considered when analyzing these results.

\section{CONCLUSION}

Sleeve and bypass were effective in restoring the liver histology of most operated patients. BMI and blood glucose showed significant improvement in both surgical techniques, with no significant difference in results between them. The levels of alkaline phosphatase, ferritin, gamma-GT and ALT decreased significantly only in the bypass group, but they did not differ from the valuesobserved in the sleeve. However, the bypass showed significantly better results in the change of the NAS score than the sleeve.

\section{REFERENCES}

1. AlgoonehA,AlmazeediS,Al-SabahS, etal.Nonalcoholicfattyliverdisease resolutionfollowing Sleevegastrectomy.Surg Endosc.2016;30(5):1983-7.

2. AlmogyG,CrookesPF,AnthoneGJ.Longitudinalgastrectomyasatreatment for the high-risk super-obese patient. Obes Surg. 2004;14(4):492-7.

3. AngrisaniL, SantonicolaA, lovinoP, etal. Bariatricsurgeryandendoluminal procedures:IFSOworldwidesurvey2014.Obes Surg.2017:27(9):2279-89.

4. AngrisaniL, SantonicolaA, lovinoP, etal.Bariatricsurgeryandendoluminal procedures:IFSOworldwidesurvey2014.ObesSurg.2017;27(9):2279-89.

5. Barros F, Negrão M G, Negrão G G. Weight loss comparison after Sleeve and Roux-en-Y Gastric Bypass: systematic review. ABCD, Arq. Bras. Cir. Dig. 2019; 32(4): e1474.

6. Beymer C, Kowdley KV, Larson A, et al. Prevalence and predictors of asymptomaticliverdiseasein patientsundergoing gastric Bypasssurgery. Arch Surg. 2003;138(111):1240-4.

7. Billeter AT, Senft J, Gotthardt D, et al. Combined non-alcoholic fatty liver disease and type 2 diabetes mellitus: Sleeve gastrectomy or gastric Bypass? - a controlled matched pair study of 34 patients. Obes Surg. 2016;26(8):1867-74

8. Bower G, Athanasiou T, Isla AM, et al. Bariatric surgery and nonalcoholic fatty liver disease. Eur J Gastroenterol Hepatol. 2015;27(7):755-68.

9. Caiazzo R, Lassailly G, Leteurtre E, et al. Roux-en-Y gastric Bypass versus adjustable gastric banding to reduce nonalcoholic fatty liver disease: a 5-year controlled longitudinal study. Ann Surg. 2014;260(5):893-8; discussion 898-9.

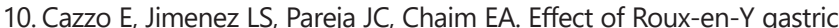
Bypass on nonalcoholic fatty liver disease evaluated through NAFLD fibrosis score: a prospective study. Obes Surg. 2015;25(6):982-5.

11. Chalasani $N$, Younossi Z, Lavine JE, et al. The diagnosis and management of non-alcoholic fatty liver disease: practice guidance from the American AssociationfortheStudy ofLiverDeseases. Hepatology, vol67, no 1,2018.

12. Chavez-Tapia NC, Tellez-Avila FI, Barrientos-Gutierrez T, et al. Bariatric surgery for non-alcoholic steatohepatitis in obese patients. Cochrane Detabase Syst Rev. 2010; 20(1):CD007340.

13. Clark JM, Alkhuraishi AR, Solga SF, et al. Roux-en-Y gastric Bypass improves liver histology in patients with non-alcoholic fatty liver disease. Obes Res. 2005;13(7):1180-6.

14. Deitel M, Gagner M, Erickson AL, Crosby RD. Third international summit: currentstatusofSleevegastrectomy.Surg Obes RelatDis. 2011;7:749-759.

15. Froylich D, Corcelles R, Daigle C, et al. Effect of Roux-en-Y gastric Bypass and Sleevegastrectomyon nonalcoholic fattyliverdisease:acomparative study. Surg Obes Relat Dis. 2016;12(1):127-31.

16. KarczWK,KrawczykowskiD,KuestersS, etal.InfluenceofSleevegastrectomy on NASH and type 2 diabetes mellitus. J Obes. 2011;2011:765473.

17. KirkilC,AygenE, Korkmaz MF, Bozan MB. Quality of lifeafterlaparoscopic Sleeve gastrectomy using baros system. ABCD, arq. bras. cir. dig. 2018; 31(3): e1385. 
18. Kleiner DE, Brunt EM, Van Natta M, et al. Design and validation of a histologicalscoring systemfornonalcoholicfattyliverdisease. Hepatology. 2005;41(6): 1313-21.

19. Lassailly G, Caiazzo R, Buob D, et al. Bariatric surgery reduces features of non-alcoholicsteatohepatitisinmorbidlyobesepatients.Gastroenterology. 2015; 149:377-88

20. MarchesiniG, Roden M, VettorR, etal. The management ofnon-alcoholic fatty liver desease, EASL, EASD, EASO Clinical Practice Guidelines.The Journal of Hepatology, vol 64, 2016.

21. Mattar SG, Velcu LM, Rabinovitz M, et al. Surgically-induced weight loss significantly improves nonalcoholic fatty liver disease and the metabolic syndrome. Ann Surg. 2005;242(4):610-7; discussion 618-20

22. Moretto M, Kupski $C$, da Silva VD, et al. Effect of bariatric surgery on liver fibrosis. Obes Surg. 2012;22(7):1044-9.

23. Mottin CC, Moretto M, Padoin AV, et al. Histological behavior of hepatic steatosis in morbidly patients with obesity after weight loss induced by bariatric surgery. Obes Surg. 2005;15(6):788-93.

24. Mummadi RR, Kasturi KS, ChennareddygariS, Sood GK. Effect of bariatric surgery on nonalcoholic fatty liver disease: systematic review and metaanalysis. Clin Gastroenterol Hepatol. 2008;6(12):1396-402.

25. NCD Risk Factor Collaboration (NCD-RisC). Trends in adult body-mass index in 200 countries from 1975 to 2014: a pooled analysis of 1698 population-based measurement studies with 19.2 million participants. Lancet. 2016;387:1377-96.

26. Palermo M, Serra E, Duza G. N-Sleeve gastrectomy: an option for obesity and GERD. ABCD, arq. bras. cir. dig. 2019; 32(4): e1482.
27. Peterli R, Wölnerhanssen BK, Peters T, et al. Effect of Laparoscopic Sleeve Gastrectomy vs Laparoscopic Roux-en-Y Gastric Bypass on Weight Loss in Patients With Morbid Obesity: The SM-BOSS Randomized Clinical Trial. JAMA. 2018 Jan 16:319(3):255-265.

28. Praveen Raj P, Gomes RM, Kumar $S$, et al. The effect of surgically induced weight loss on nonalcoholic fatty liver disease in morbidly obese Indians: "NASHOST" prospective observational trial. Surg Obes Relat Dis. 2015:11(6):1315-22.

29. SaadehS, YounossiZM, RemerEM, etal. The utility of radiological imaging innonalcoholicfattyliverdisease. Gastroenterology.2002;123(3):745-50.

30. Salminen P, Helmio M, Ovaska J, et al. Effect of Laparoscopic Sleeve Gastrectomyvs LaparoscopicRoux-en-YGastricBypasson WeightLossat 5 year among patients with morbid obesity: the Sleevepass randomized clinical trial. JAMA 2018 Jan 16;319(3):241-254.

31. SchauerPR,BhattDL, KirwanJP, etal.Bariatricsurgeryversusintensivemedical therapy for diabetes - 5 year outcomes. N Engl J Med. 2017:376:641-51

32. Vargas V, Allende $H$, Lecube A, et al. Surgically induced weight loss by gastric Bypass improves non-alcoholic fatty liver disease in morbid obese patients. World J Hepatol. 2012;4(12):382-8.

33. Williams CD, Stengel J, Asike MI, et al. Prevalence of nonalcoholic fatty liver disease and nonalcoholic steatohepatitis among a largely middleaged population utilizing ultrasound and liver biopsy: a prospective study. Gastroenterology. 2011; 140(1):124-31.

34. Zilberstein B, Santo M A, Carvalho M H. Critical analysis of surgical treatment techniques of morbid obesity. ABCD, arq. bras. cir. dig. 2019; 32(3): e1450. 